\title{
A UTILIZAÇÃO DE TÉCNICAS TERAPÊUTICAS AUXILIARES NA RESOLUÇÃO DE CONFLITOS PELO JUDICIÁRIO BRASILEIRO
} THE USE OF AUXILIARY THERAPEUTIC TECHNIQUES IN THE RESOLUTION OF CONFLICTS BY THE BRAZILIAN JUDICIARY

\begin{tabular}{l|} 
RVD \\
Recebido em \\
06.05 .2020 \\
Aprovado em \\
21.07 .2020
\end{tabular}

Érica Brito Gomes ${ }^{1}$

\author{
Ana Maria Andreazza Araújo Leite ${ }^{2}$ \\ José Weidson de Oliveira Neto ${ }^{3}$
}

\section{RESUMO}

No ordenamento jurídico brasileiro, o Estado tem uma função essencial que é harmonizar os conflitos que chegam até ele. No entanto, a ideia de justiça trazida pelo Poder Judiciário não atende mais as necessidades da população, uma vez que ao buscarem a resolução do conflito encontram com a lentidão processual, circunstância que dificulta a resolução do litígio. Em vista disso, o Judiciário procura outras maneiras para um processo rápido e eficaz. O presente estudo tem a finalidade de apresentar as técnicas auxiliares aos métocos autocompositivos, que pretendem minimizar o pleito na esfera jurídica. Além disso, traz base histórica, conceituações e importância de todo esse caminho para trilhar em busca da resolução do conflito. Utiliza-se método dialético como abordagem de pesquisa, além de técnicas indiretas e exploratórias de bibliografias e documentos legislativos relevantes sobre a matéria. Assim, incentiva-se a

${ }^{1}$ Bacharela em Direito pelo UNITPAC. email: carollyne382@gmail.com

ORCID: 0000-0002-4591-5955. Rua Perimetral 01, 230, setor oeste, Araguaína-TO, CEP:77816-270

${ }^{2}$ Administradora de Empresas (UFC); MBA em Gestão Empresarial (FGV-RJ); Mestre em Administração e Controladoria, na linha de pesquisa Estudos Organizacionais e Gestão de Pessoas (UFC); Formação em Personal e Professional, Executive e Alpha Coaching (SBC); Formação em Coaching Cognititvo Comportamental (3b3C); Formação em Constelação Familiar Sistêmica e Constelação Organizacional (IBS); Desde 2010 é colaboradora do IESh (Instituto Eneagrama Shalom), integrando as equipes de Renascimento, FESh (Formação Eneagrama Shalom) no Brasil e em Portugal, Projeto PQV (Para Quê Viver?); É associada à International Enneagram Association (IEA Brasil); email: andreazzaleite@gmail.com - ORCID 0000-0003-4050-7394 Rua J P Morgan, 100 / casa 50 / Bairro: N. S. Lourdes CEP 60.191-100, Fortaleza - CE

${ }^{3}$ Mestre em direito constitucional pela Universidade de Fortaleza, professor do Centro Universitário Tocantinense Presidente Antonio Carlos, Presidente da Seção do Tocantins da Associação De Direito de Família e das Sucessões, Advogado. email: professorweidson@gmail.com - ORCID 0000-0002-45425489 Rua Adevaldo de Moraes, 190, casa 2, Loteamento Manoel Gomes da Cunha, Araguaína, Tocantins, Cep 77818-090. 
https://doi.org/10.20873/uft.2359-0106.2020.v7n2.p426-448

utilização do direito sistêmico e suas técnicas auxiliares, como por exemplo, as oficinas de parentalidade, na contribuição de resoluções consensuais de conflitos judiciais.

Palavras-chaves: Autocomposição. Conflito. Constelação familiar. Mediação. Poder Judiciário.

\begin{abstract}
In the Brazilian legal system, the State has an essential function, which is to harmonize the conflicts that come to it. However, the idea of justice brought by the Judiciary no longer meets the needs of the population, since when seeking the resolution of conflict, they encounter with the procedural slowness, a circumstance that makes it difficult to resolution of the dispute. In view of this, the Judiciary looks for other ways for a fast and effective process. The present study aims to present the auxiliary techniques to "self compositive" methods, which intend to minimize the claim in the legal sphere. In addition, it brings historical basis, conceptualizations and importance of all this path to walk in search of the resolution of the conflict. Dialectical method is used as a research approach, in addition to indirect and exploratory techniques of bibliographies and relevant legislative documents on the subject. Systemic law and its techniques can contribute, through parenting workshops, to the consensual resolution of legal conflicts.
\end{abstract}

Keywords: Self-composition; Conflict. Family constellation. Mediation. Judicial Power.

\title{
1 CONSIDERAÇÕES INICIAIS
}

Os conflitos de interesses sempre existiram em qualquer sociedade e, via de regra, são motivos de angustia no meio social e por isso a pacificação social é sempre almejada. Pode-se dizer que atualmente, um dos principais desafios do Judiciário é desenvolver procedimentos que sejam considerados justos pelos próprios jurisdicionados, não apenas em razão dos seus resultados, mas também em função da forma de participação dos envolvidos.

Faz-se necessário evidenciar que a autocomposição é uma forma legítima de solução de conflito, meio alternativo incentivado pelo direito para a propagação de resoluções consensuais. Com vistas à maximizar os resultados já positivos da autocomposição, muitas técnicas auxiliares, com potencial para resolução de conflitos, tem surgido. Neste sentido, questiona-se: o direito sistêmico tem auxiliado o Poder Judiciário na resolução pacifica de conflitos?

Deste modo, como objetivo geral apresenta-se um modelo alternativo do processo convencional e analisa-se todos os meios autocompositivos que contribuem 
https://doi.org/10.20873/uft.2359-0106.2020.v7n2.p426-448

para uma maior celeridade processual, trazendo para as partes um sentimento de justiça feita, fazendo que ambos saiam satisfeitos com o acordo entabulado.

Tal artigo tem como objetivo específico, compreender a importância e a aplicabilidade das técnicas auxiliares, em especial, demonstrar-se a finalidade da autocomposição, apresentando também técnicas pouco conhecidas que trazem grandes soluções.

A pesquisa realizada é bibliográfica, com ênfase em artigos específicos do tema, assim como em dados disponíveis em sítios da internet e outros documentos jurídicos. A pesquisa é qualitativa em seu aspecto geral, mas são utilizados dados constantes em sítios de domínio público. Quanto ao método de abordagem, utiliza-se o dialético, uma vez que se estabelece diálogo entre as fontes com vistas à compor uma síntese.

\section{MÉTODOS AUTOCOMPOSITIVOS E A CULTURA DO CONSENSO}

Tão natural quanto as relações humanas é o conflito interpessoal. É certo que a convivência afetiva ou laboral gera desentendimentos na vida cotidiana. Ao atrair a incidência da norma jurídica para estes conflitos, os mesmos se tornam fatos jurídicos, e, quando levados à apreciação do Poder Judiciário, fazem nascer a lide ou o litígio.

O conflito é definido como uma crise na interação humana, é inerente à condição de ser pessoa, pois cada indivíduo possui sua particularidade, vive em seu contexto e sua realidade (TARTUCE, 2019). O que se quer dizer, na esteira da fenomenologia da percepção de Merleau-Ponty (1999), é que as individualidades levam a percepções diferentes que, de forma frequente, ocasionam embates e conflitos. Todo ser é único. $O$ misto de individualidades inseridas em sociedade produz, naturalmente, o conflito.

O conflito, em si, não é algo negativo, ao contrário, pode ser bastante construtivo. Entretanto, por muitas vezes, administrado de maneira errônea, carrega uma conotação negativa. Adequadamente administrado, pode promover satisfação e melhorar a qualidade de vida dos envolvidos. (SALES, 2007). Nisto, o direito tem evoluído, no sentido de encontrar respostas à questão: como melhorar e otimizar as 
https://doi.org/10.20873/uft.2359-0106.2020.v7n2.p426-448

resoluções de conflitos judicializados, notadamente, no âmbito das ações de família? A interdisciplinaridade pode ser uma solução interessante.

No Brasil, o ordenamento jurídico, notadamente no âmbito do direito processual, tem passado por atualizações significativas, dentre elas, destaca-se a influência internacional convergente no âmbito de desenvolver e aprimorar os métodos de solução consensual de demandas judiciais.

A ênfase nestes meios de solução consensual surge a partir de problemas graves enfrentados pelo Poder Judiciário, como o número excessivo de processos e a falta de celeridade na tramitação deles, entre outros.

De acordo com o Conselho Nacional de Justiça (CNJ) no Relatório Justiça em Números, nos anos de 2015 e 2016, foi constatado que a Justiça Estadual conserva aproximadamente $80 \%$ dos processos de todo o Poder Judiciário. No mesmo período de apuração, verifica-se o aumento de cerca de trinta milhões de casos novos (dois milhões a mais do que os casos novos que ingressaram em 2015), dos quais cerca de vinte milhões foram destinados à Justiça Estadual. O aumento de casos pendentes também é significativo: a evolução chega à marca de 6 milhões no Poder Judiciário brasileiro, dos quais 4 milhões estão na Justiça Estadual (CNJ, online).

Mais recentemente, o Relatório Justiça em Números de 2019, enuncia que:

[...] o Poder Judiciário finalizou o ano de 2018 com 78,7 milhões de processos em tramitação, aguardando alguma solução definitiva. Destes, 14,1 milhões, ou seja, $17,9 \%$, estavam suspensos, sobrestados ou em arquivo provisório, aguardando alguma situação jurídica futura. Dessa forma, desconsiderados tais processos, tem-se que, em andamento, ao final do ano de 2018 existiam 64,6 milhões ações judiciais. (ASSOCIAÇÃO DOS NOTÁRIOS E REGISTRADORES DO BRASIL, online)

Em 2019, a Justiça Estadual corresponde à $80 \%$ de todos os casos do Poder Judiciário, totalizando mais de 60 milhões de processos.

Os números assustam. O processo lento, a pequena quantidade de magistrados e o acesso à justiça com o valor alto, gera um sentimento de abandono e de injustiça no cidadão. Por razões como estas, urge a necessidade de adotar novas medidas para a resolução de conflitos judiciais, de forma a obter um processo mais célere e que garanta maior satisfação para as partes em litígio. 


\section{https://doi.org/10.20873/uft.2359-0106.2020.v7n2.p426-448}

Para tanto, a ciência jurídica desenvolveu novos meios de solução de conflitos, visando obter uma maior celeridade e eficiência. No processo civil, fala-se em métodos auto compositivos, dos quais destacam-se: arbitragem, mediação e conciliação.

A arbitragem é um meio privado de solução de conflitos, alternativo à solução judicial, desde que esses conflitos sejam decorrentes de direitos patrimoniais e disponíveis, onde um terceiro independente e imparcial recebe o poder de uma convenção para decidir um litígio por elas, sendo que a sua decisão equivale a uma sentença judicial. (SCAVONE JUNIOR, 2018).

A conciliação é uma ferramenta de resolução de conflitos em que as partes agem em conjunto com um terceiro, que propõe soluções, na busca pela melhor solução para o conflito. No entanto, a condução conciliatória é realizada ativamente pelo terceiro, imparcial, que conduz as partes à uma solução jurídica e real viável para o litígio entre as partes. Não obstante que haja a participação ativa do conciliador, o consenso entre as partes é o elemento essencial para a resolução da lide. (DELGADO, 2017). Por sua vez, pode-se afirmar que a mediação é um mecanismo de solução de conflitos que tem como argumento o diálogo inclusivo e cooperativo entre os indivíduos e a participação de um terceiro imparcial - o mediador - que, com a capacitação adequada, facilita a comunicação entre os litigantes sem propor ou sugerir, possibilitando a construção de uma solução satisfatória pelas próprias partes. (SALES, 2016).

\subsection{A valorização da mediação no Judiciário brasileiro}

Dentre os métodos auto compositivos, a mediação tem ganho bastante destaque no cenário nacional. A mediação é um dos vários mecanismos chamados de meios alternativos onde as partes, dialogando, questionando ou sugerindo, com o auxílio de um terceiro imparcial chegam ao um interesse comum, ou seja, o acordo.

A mediação possibilita, por meio de técnicas próprias utilizadas pelo mediador, a identificação do conflito real vivenciado e a sua solução. A mediação requer a discussão sobre as posições, interesses e valores envolvidos e, a partir da ressignificação desses valores, permite a construção participativa do consenso. (SALES, 2016). 


\section{https://doi.org/10.20873/uft.2359-0106.2020.v7n2.p426-448}

Em suma, a mediação contribui para a resolução consensual do conflito, por meio do auxílio de um terceiro (mediador) neutro, que intermedia uma conversa com as partes com a finalidade alcançar o acordo. No entanto, o mediador não propõe soluções, apenas auxilia o diálogo das partes. O protagonismo é das próprias partes.

A mediação foi introduzida primariamente nas legislações da Argentina, Uruguai, Japão, França, entre outros. O conselho da União Europeia, por sua vez, emitiu uma diretiva onde definia a mediação como um procedimento organizado em que as partes, por si mesmas, alcançavam um acordo para a solução do conflito. (CABRAL, 2017).

É importante destacar que estas ações eram feitas de forma involuntária. Assim, nestes períodos, ainda não havia uma categorização ou conceituação organizada acerca deste método, apenas após a percepção e teorização, é que a mesma foi assim designada e puderam ser apropriadamente catalogados como momentos de ocorrência com características peculiares e certamente definidas. (FARIAS, 2016).

No Brasil, a mediação começou na década de 1980 e sua inclusão aconteceu com a chegada de profissionais de 71 países, com conhecimento técnico para palestrar e fomentar a discussão do tema. (BRAGA NETO; SALES, 2012). Desse modo, houve uma exigência para normatização da mediação no ordenamento jurídico brasileiro, de modo a estruturar sua forma junto ao Judiciário brasileiro, com vistas a alcançar maior efetivação.

O Conselho Nacional de Justiça (CNJ), com intuito de modernizar a Justiça brasileira, vem iniciando várias atitudes pra impulsionar os meios consensuais de resolução dos conflitos, têm-se como exemplo o projeto "Movimentos pela Conciliação". (CABRAL, 2017).

No mesmo sentido, editou-se a Resolução n.- 125/2010 do CNJ, que desde sua ementa concede ao Poder Judiciário a responsabilidade de abranger, na sua organização, políticas públicas de meios consensuais. Este documento representou um grande avanço na cultura do consenso no país.

A Resolução № 125/2010 implementou a Política Judiciária Nacional no tratamento dos conflitos, otimizando a prática e determinando que os órgãos judiciais disponibilizassem meios de solução consensual, como a mediação e a conciliação, à população. (GONÇALVES; RODRIGUES; LAHOZ, 2018) 
https://doi.org/10.20873/uft.2359-0106.2020.v7n2.p426-448

Outro significativo avanço foi a edição do novo Código de Processo Civil, Lei $n$. 13.105, de 16 de março de 2015, uma vez que o antigo diploma (Código de Processo Civil de 1973) não trazia qualquer previsão sobre a mediação, apesar de mencionar a conciliação.

O artigo 166 do Código de Processo Civil de 2015 inovou ao trazer a obrigatoriedade de audiência de autocomposição, o que representa um estímulo visível à mediação. Como dita Medeiros Neto e Nunes (2019), são vários artigos no CPC que tratam sobre a mediação, mostrando que a intenção do legislador é trazer à tona o princípio da autonomia da vontade e privilegiar meios consensuais para a resolução das demandas.

As disposições da Resolução no 125/2010 - CNJ foram reiteradas pelo artigo 165 do CPC, que estabelece a Política Nacional de tratamento adequado das divergências de relevância no esfera do Poder Judiciário, submetendo a instauração dos Centros Judiciários de Solução de Conflitos e Cidadania - CEJUSCs, tendentes a garantir outros métodos para solução de controvérsias, especialmente os identificados como meios consensuais, por exemplo, a mediação e a conciliação. Tudo isto em vista da promoção teleológica da cidadania (MEDEIROS NETO; NUNES, 2019).

Assim, o Código de Processo Civil condiciona com aspectos positivos a prática dos meios consensuais e institui amplo marco na obtenção da equanimidade, funcionando como uma legislação protagonista na promoção da cultura do consenso no Brasil.

Em paridade com o Código de Processo Civil, no dia 29 de junho de 2015, foi aprovada a Lei n 13.140/2015 (lei de Mediação), que trata sobre a mediação como um meio alternativo ao litigio e sobre a autocomposição nas lides no ramo da administração pública. Assim, ficou instaurado um marco de normatização sobre este mecanismo consensual.

A referida lei traz a mediação como uma metodologia elaborada por um terceiro imparcial, mas, sem ser uma autoridade decisiva, apenas instiga as partes a constatarem e realizarem uma melhor solução do conflito.

Neste sentido, ressalta-se a importância do amparo legal aos métodos auto compositivos. No entanto, é igualmente relevante que comunidade compreenda a 
https://doi.org/10.20873/uft.2359-0106.2020.v7n2.p426-448

cultura da paz, afastando-se da perspectiva do conflito. A mediação, por exemplo, é um método que necessita de reconhecimento, pois é dispositivo competente para as soluções de conflitos. Logo, toda a comunidade jurídica - acadêmicos, advogados, juízes, entre outros - precisam conhecer e praticar os métodos auto compositivos com vistas a dar eficácia às novas normativas.

\subsection{CEJUSC: Criatividade e inovação para o Judiciário brasileiro}

O Centro Judiciário de Solução de Conflito e Cidadania foi introduzido pela Resolução 125/2010 do CNJ que deliberou sobre sua criação, para que as partes tenham acesso preliminar à resolução consensual de suas contendas. (SOUZA, 2019).

Conforme o Conselho Nacional de Justiça, os Centros Judiciários de Solução de Conflitos e Cidadania - CEJUSCs foram inspirados em experimentos passados, como a lei dos Juizados Especiais (lei n. 9.099/1995). (CNJ, online)

Percebe-se que, com a criação dos CEJUSCs e das politicas públicas de autocomposição, há uma quebra da cultura institucionalizada de que a solução do conflito é dada por um magistrado. Com isso, o papel de resolução passa a ser dos próprios litigantes, trazendo sua atuação direta, com o auxílio do mediador/conciliador. (SANTOS, 2018).

O CEJUSC é a institucionalização da promoção da cultura do consenso no Judiciário brasileiro, é por meio dele que a mediação e a conciliação têm alcançado cada vez mais destaque e sucesso no cenário nacional. De acordo com o Relatório Justiça em Números, no ano base 2015, foi revelado um índice de conciliação em $11 \%$ das sentenças, resultando aproximadamente 2,9 milhões de processos finalizados de maneira autocompositiva ( $\mathrm{CNJ}$, online). 
Gráfico 1: Índice de Conciliação no Poder Judiciário (CNJ, online)

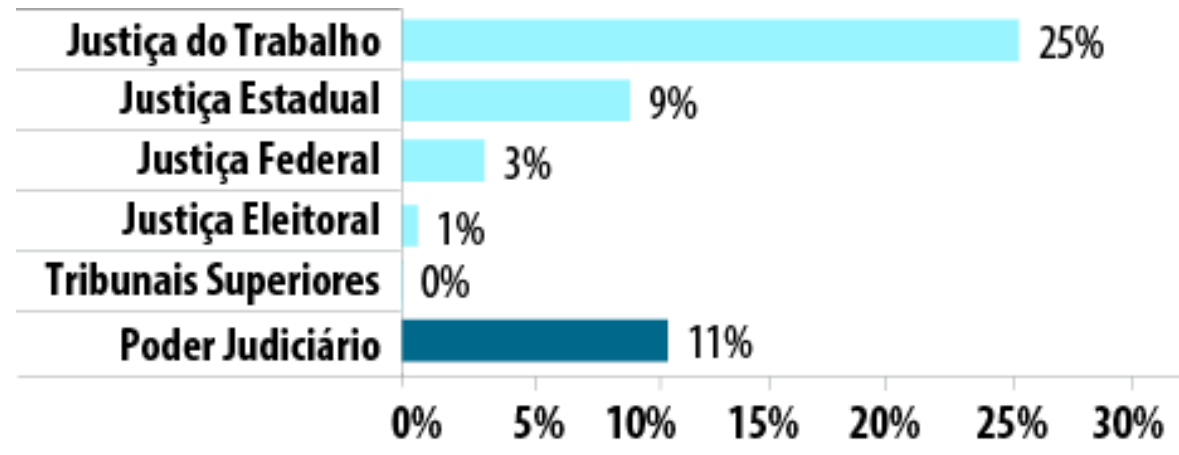

Fonte: <https://www.cnj.jus.br/relatorio-justica-em-numeros-traz-indice-de-conciliacao-pela-1-vez/>

O índice de conciliação na Justiça Estadual brasileira foi de 9,4\% com média de 1,8 milhão de sentenças finalizadas com acordo. A justiça do Trabalho está em primeiro, com $25,3 \%$ das sentenças e decisões obtidas com a conciliação: em média de 1 milhão de processos. Já a Justiça Federal está com 3\% das sentenças: 105mil. (CNJ, online)

Esta criação foi iniciativa criativa para que os CEJUSCs abram as portas do judiciário à interdisciplinaridade com outras ciências para a promoção de acordos na resolução de conflitos judiciais.

\section{INTERDISCIPLINARIDADE COMO SOLUÇÃO PARA RESOLUÇÃO CONSENSUAL DE DEMANDAS JUDICIAIS: NOVAS TÉCNICAS AUXILIARES}

Em meio ao aumento das situações de conflito, muitas técnicas tem sido desenvolvidas com a finalidade de auxiliar nas resoluções. Surge, então, a questão: algumas dessas técnicas poderiam auxiliar o Judiciário na resolução consensual de suas demandas? A resposta é positiva, no entanto, carece de maior discussão, aprofundamento e estruturação.

Assim, as novas técnicas auxiliares surgiram como novos rumos a serem caminhados optativamente pelo Poder Judiciário, para que resolvam os litígios de modo distinto ao procedimento tradicional, mais formal, menos célere e com decisão tomada por um terceiro. Tais técnicas são de natureza social, prática e, não necessariamente, 
https://doi.org/10.20873/uft.2359-0106.2020.v7n2.p426-448

científica. No entanto, o Judiciário pode adaptá-las e gozar de seus resultados positivos.

\subsection{Justiça Restaurativa}

A Justiça Restaurativa é constituída por um conjunto ordenado e sistêmico de concepções, estratégia, técnicas e atividades próprias, que objetiva a conscientização sobre os fatores relacionados, institucionais e sociais motivadores de conflitos e violência, e por meio do qual os conflitos que geram dano, concreto ou abstrato, são solucionados de modo estruturado. (CNJ, online). Neste sentido, tem-se:

A justiça restaurativa constitui-se como um conjunto ordenado e sistêmico de princípios, métodos, técnicas e atividades próprias, que visa à conscientização sobre os fatores relacionais, institucionais e sociais motivadores de conflitos e violência, e por meio do qual os conflitos que geram dano, concreto ou abstrato, são solucionados de modo estruturado(CNJ, online)

A justiça restaurativa inaugura uma nova percepção sobre o conflito, a partir do Poder Judiciário. As pessoas envolvidas (ofendida e ofensor) são chamadas para dialogar de forma democrática e horizontal para que possam expressar seus sentimentos e necessidades e que possam estabelecer acordos. (BRAGA, 2014).

A Justiça Restaurativa não é uma ocorrência moderna, vez que remonta a antiguidade; mais diretamente quando as pessoas se agrupavam nas cavernas com o objetivo de dialogar e resolver a lide presente. É certo que naquela época não havia o padrão de Estado moderno que se tem hoje, com estruturas e formalidade definidas, o que favorecia a simplicidade dos diálogos, mas não facilitava a condensação de uma metodologia aplicável. No entanto, os princípios de auto composição ali já eram vislumbrados. (BRAGA, 2014).

Elenice da Silva (2017) relata que as notícias primárias sobre a Justiça Restaurativa são do século $X X$, na região Canadense, em penitenciárias, com o pretexto de proporcionar a solução do conflito. Deste modo, é viável marcar o Canadá como um grande colaborador na organização da prática restaurativa.

Outro modelo semelhante e que utiliza as práticas de autocomposição são as aldeias hindus da Índia, especialmente o sistema de justiça panchayat. Neste, uma 
https://doi.org/10.20873/uft.2359-0106.2020.v7n2.p426-448

turma de cinco pessoas, tanto auxilia na disputa como árbitra, como praticam funcionalidades que levam ao conforto dentro da aldeia. (MOORE, 1998).

Já no Brasil, a Justiça Restaurativa foi instruída em 2005, por meio da Secretaria da Reforma do Judiciário que agiu de forma a proporcionar o projeto chamado "Promovendo Práticas Restaurativas do Sistema de Justiça Brasileiro". Em colaboração com o Programa das Nações Unidas para o Desenvolvimento (PNUD), foram executados esquemas restaurativos em dois estados brasileiros (São Paulo e Rio Grande do Sul) e no Distrito Federal (ORTEGAL, 2006).

A justiça restaurativa chegou como um método de modificação da comunidade, já que estimula o acesso de maneira comunicativa para a promover a paz social, possibilitando a conciliação das vítimas e, aos ofensores, a solução para o contratempo do conflito social. (NUPEMEC, 2011).

A técnica restaurativa é espontânea e sigilosa, realizada por facilitadores especializados em Justiça Restaurativa, que auxiliam o diálogo para que as partes possam construir uma solução mais adequada para si. (TRIBUNAL DE JUSTIÇA DO DISTRITO FEDERAL E DOS TERRITÓRIOS, 2019).

Primeiramente, são realizadas sessões individuais para averiguar se há possibilidades de sessões conjuntas, que somente acontecem se o ofensor assumir a responsabilidade e a vítima transparecer o trauma decorrente do crime. Caso as partes concordem com um acordo, é confeccionado um termo restaurativo, que é encaminhado para o magistrado para verificar os requisitos legais e colher parecer do Ministério Público. Nos crimes de menor potencial ofensivo, esse acordo pode extinguir o processo, já nos crimes de médio e alto potencial ofensivo, o termo é dado como fixação de pena. (TRIBUNAL DE JUSTIÇA DO DISTRITO FEDERAL E DOS TERRITÓRIOS, 2019).

Assim como a justiça restaurativa auxilia o Judiciário nas demandas judiciais, trazendo um novo tratamento para a matéria da infração, possibilitando um referencial humanitário com a pacificação nas relações sociais conflituosas, a contestação familiar, outro método auxiliar, também tem auxiliado o Judiciário na busca de soluções consensuais. 


\subsection{Constelação Familiar}

A Constelação Familiar foi desenvolvida pelo psicoterapeuta alemão Bert Hellinger (1925 - 2019), a partir da síntese de seu percurso acadêmico na filosofia, teologia, pedagogia e psicanálise, aliados à sua experiência de 16 anos de trabalho como missionário junto aos zulus, na África do Sul (NEUHAUSER (org.), 2006).

Por meio de uma fenomenologia filosófica e psicoterapêutica, a Constelação Familiar permite a ampliação da consciência dos emaranhamentos presentes em um sistema, que causam conflito ou desordem e possibilita novas escolhas e ações conscientes rumo à solução.

A constelação é um paradigma psicoterápico possuindo como finalidade básica de estudo a energia e as emoções, que são acumuladas através de todas as pessoas por meio de uma abordagem de forma sistêmica, conclui criando a percepção de todos as causas que se encontram incluídos no desacordo. (XVI SEMINÁRIO INTERNACIONAL DEMANDAS SOCIAIS E POLÍTICAS PÚBLICAS NA SOCIEDADE CONTEMPORÂNEA, 2019).

O conceito do termo constelação atribui-se ao coletivo de estrelas que constitui um sistema. Em resultância deste significado é que se formou a palavra constelação familiar, onde pode-se verificar o ser humano como sendo centro do sistema comunitário que se encontra adentrado e acaba passando naquele período específico da constelação (HAUSNER, 2007).

A constelação familiar facilita na compreensão e, em consequência, na correção de padrões de comportamentos inadequados que, por esta razão, levam a dor, sofrimentos e conflitos. Deste modo, contribui nos casos com obstáculos para resolução da lide, ajuda a fluir o campo de relacionamento familiar, social e organizacionais (CARMO, 2015).

Conforme Hellinger, a constelação familiar tem o alicerce nas Ordens do Amor, que são constituídas por três leis sistêmicas nomeadas como Pertencimento, Hierarquia e Equilíbrio, que regem e mantêm todos os sistemas humanos.

Pelo Pertencimento, todos os membros de um sistema têm o direito a pertencer e estão ligados por forças de lealdade, fazendo com que, em casos de exclusão, algum 
https://doi.org/10.20873/uft.2359-0106.2020.v7n2.p426-448

outro membro, mesmo de gerações posteriores, desenvolva uma identificação com o excluído, repetindo, de forma inconsciente, padrões de sentimento e comportamento.

A Hierarquia mantém ordem ao reconhecer que, os que vêm primeiro em um sistema têm primazia pelos que vêm depois. Ou seja, os mais antigos devem ser honrados, respeitados e reverenciados. Pelo Equilíbrio, entende-se que, para um sistema ser sustentável, é necessário que haja um equilíbrio entre o dar e o receber. Portanto, se uma parte doa ou recebe mais, essa relação tende a romper-se.

Cada uma dessas três necessidades sujeita o indivíduo a atividades que estimulam suas necessidades e propósitos pessoais, policiando, ordenando obediência. Procedendo como leis que suprimem vontades de expressões individuais, mas também tornam prováveis os relacionamentos particulares entre os indivíduos (HELLINGER, 2015).

Neste sentido, as ordens de amor são forças descontraídas e articuladoras que permeiam famílias ou relacionamentos particulares, e, quando se apresentam em padrões não resolvidos, causam conflito, desordem e inquietação. Assim, por meio do entendimento das leis sistêmicas, os indivíduos são capazes de descobrir soluções transformadoras pautadas na dinâmica do amor.

Em uma sessão de constelação, o cliente é acompanhado por um terapeuta, denominado constelador, que o convida a escolher, em meio ao grupo, representantes para as pessoas que compõem o seu sistema. Os representantes são colocados, pelo cliente, em cena, um em relação ao outro, conforme sua imagem interior. Segundo Hellinger (2001), "Através desse processo, o cliente é surpreendido por algo que subitamente vem à luz".

Significa que há uma nova percepção sobre algo que antes estava no inconsciente da pessoa e de seu sistema familiar. E quando muda o olhar, mudam os sentimentos e os comportamentos. Então, é possível encontrar a solução e restabelecer o equilíbrio sistêmico, permitindo que o amor floreie, como afirma Hellinger (2015) "Penetrar as ordens do amor é Sabedoria. Segui-las com amor é humildade".

Diante desse cenário, entende-se que, para o indivíduo atingir aquilo que deseja, deve especialmente, dissipar as fronteiras concedidas pelo consciente e inconsciente, 
https://doi.org/10.20873/uft.2359-0106.2020.v7n2.p426-448

dando abertura para novas ideias, opiniões e princípios, afastando tudo que não the acrescentava.

Assim, é aceitar o novo olhar que Hellinger (2001) preceitua, que é crescer, conhecer, aprimorar o campo de visão, de forma que a sabedoria dessas ordens do amor mudará para o ponto de partida, trazendo as resoluções de conflitos familiares, e por seguinte, a cura.

Em vista disso, a ciência elaborada por Hellinger inserida no ambiente jurídico potencializa a transformação, pois as constelações familiares concedem aos indivíduos novos meios de resolução do conflito, levando-os à raiz da questão, abrindo a probabilidade de mudança.

A constelação estimula os indivíduos a se olharem com atenção e aceitação, e assim, propicia a reestruturação de algo que estava pesado e destrutivo, para uma composição mais leve, fluída, consciente e pacificadora.

\subsection{Oficina de parentalidade}

Os Tribunais de Justiça brasileiros, ajustando-se à nova tendência autocompositiva e aberta às novas técnicas, têm realizado as chamadas oficinas de parentalidade, com ênfase em auxiliar nos conflitos de ordem familiar.

As oficinas de parentalidade são inspiradas em métodos de outros países, como Canadá e Estados Unidos, com intuito de auxiliar famílias envolvidas em conflitos judicializados, tais como dissolução de vínculo ou sociedade conjugal, guarda de filhos e prestações alimentícias. (BRITO; SILVA, 2017).

No Brasil, a Oficina de Parentalidade foi uma iniciativa do Conselho Nacional de Justiça (CNJ) com o objetivo primordial de promover o diálogo entre pais e mães que passam por conflitos relativos a separação conjugal. (TRIBUNAL DE JUSTIÇA DO DISTRITO FEDERAL E DOS TERRITÓRIOS, 2019)

A ideia da oficina de parentalidade tem finalidade preventiva e educacional, levando pais e filhos a entenderem que a separação é somente dos cônjuges, e que o elo familiar não é rompido com o término do casamento. Pelo contrário, o vínculo entre as pessoas continua, em proveito da criação dos filhos. 
https://doi.org/10.20873/uft.2359-0106.2020.v7n2.p426-448

Com a instauração da oficina de parentalidade, espera-se que se possam colher os melhores frutos, desde a promoção de famílias mais saudáveis e maduras socialmente, como com o aumento do número de soluções consensuais no Poder Judiciário, e até mesmo a redução da judicialização de conflitos familiares.

Além disso, importa ressaltar que as oficinas de parentalidade, promovidas pelos Tribunais de Justiça, também realizam uma importante função social: o fomento à cultura da paz e do consenso. A sua fama e o seu sucesso alcançam toda a comunidade jurídica, o que é de grande valia, dada a necessidade de que advogados, promotores e demais serventuários conscientizem-se acerca dos benefícios do consensualismo e da desjudicialização de determinadas causas.

As oficinas de parentalidade contam com material didático providenciado pelo Conselho Nacional de Justiça (CNJ), composto por cartilhas, vídeos e depoimentos gravados, que são utilizados durante as oficinas. No decorrer das oficinas, algumas atividades realizadas objetivam analises sobre a lide vivida e a relevância do diálogo, buscando sempre a solução do conflito e o entendimento familiar.

Para a coordenadora do Núcleo Permanente de Métodos Consensuais de Solução de Conflitos (Nupemec) do Tribunal de Justiça do Tocantins, a juíza Umbelina Lopes Pereira:

As oficinas auxiliam na reconstrução do diálogo entre as famílias e minimizam os traumas da separação entre o casal, possibilitando que o crescimento das crianças e adolescentes aconteça de forma emocionalmente saudável (OLIVEIRA, 2017, online).

Já o coordenador do Centro Judiciário de Solução de Conflitos e Cidadania (Cejusc) de Palmas/TO, o juiz Nelson Coelho, a importância da oficina está em promover a reconstrução familiar e amenizar os traumas ocasionados pela separação:

O auxílio é muito grande, com o tempo o cônjuge que passou pela ruptura sente dificuldades nas relações familiares; com a oficina de Parentalidade é possível orientar os filhos e os genitores que estão passando pelo conflito e com o tratamento diferenciado que eles recebem aqui, as demandas são solucionadas com mais celeridade e de forma mais pacífica (OLIVEIRA, 2017, online). 
https://doi.org/10.20873/uft.2359-0106.2020.v7n2.p426-448

O plano básico é disseminar aos pais mecanismos certos de comunicação no seio familiar, possibilitando ensinamentos sobre os efeitos do conflito para os filhos, trazendo também informações sobre alienação parental, guardas, visitas, e alimentos, tal como a compreensão de que a união chegou ao fim, mas que a relação familiar com os filhos sempre continuará. (BRITO; SILVA, 2017). Informar a comunidade, então, é outra funcionalidade ofertada quando se realizam oficinas de parentalidade.

Com relação aos processos judiciais, tem-se vários benefícios, pois os processos tendem a se alongar por longos anos para chegar ao julgamento, com isso, as pessoas se contrariam, perdem as expectativas, sem dizer que uma simples ação de divórcio pode causar outras ações, como de pensão alimentícia. Parte da morosidade frequentemente atribuída ao Judiciário brasileiro é também devida a cultura de se judicializar quase tudo, esperando a solução de um terceiro sobre os conflitos interpessoais. A cultura do consenso pretende superar este obstáculo.

Com a prolação da sentença, por muitas vezes, os juízes não conseguem satisfazer as partes, dado que uma sairá "vencedora" e a outra não. Ao contrário, quando há uma oportunidade de diálogo, as partes, na maioria das vezes, conseguem se expressar com clareza, de modo que facilitam a criação de um acordo, aumentando a sensação de satisfação com o final do processo.

Com a realidade de judicialização atual no Brasil, as pessoas pretendem conceder ao Poder Judiciário a responsabilidade de resolução de seus próprios conflitos, aborrecimentos e adversidades. A oficina de parentalidade contribui com informação e auxílio no diálogo entre as partes envolvidas, fomentando o consenso e a resolução não só do processo judicial, mas da raiz social do conflito.

$\mathrm{Na}$ tendência do direito sistêmico e das novas técnicas auxiliares à resolução consensual de demandas, as oficinas de parentalidade tornam-se instrumentos que viabilizam o emprego e o sucesso de muitas dessas ferramentas. Por um lado, a oficina de parentalidade ganha novos instrumentos eficazes ao qualificar profissionais aptos a gerenciar tais técnicas, por outro, fomenta o surgimento de novas pesquisas e novas ferramentas úteis à resolução consensual de conflitos. A interdisciplinaridade, mencionada no novo Código de Processo Civil do Brasil, torna-se real também a partir das oficinas de parentalidade. 
https://doi.org/10.20873/uft.2359-0106.2020.v7n2.p426-448

A exemplo dessa interdisciplinaridade promovida pelo Judiciário brasileiro, temse o Tribunal de Justiça de São Paulo, um dos maiores do país, que relata sua experiência positiva no âmbito das constelações familiares e das oficinas de parentalidade:

\begin{abstract}
De acordo com a juíza Claudia Marina Maimone Spagnuolo, coordenadora do Cejusc, no ano de 2018 foram realizadas nove oficinas de Constelação Familiar, com a presença de 272 partes em processos em andamento e expedientes pré-processuais, não somente do Foro Regional de Santo Amaro, mas também dos foros regionais do Butantã, Penha de França e Taboão da Serra. Também aconteceram três Oficinas de Parentalidade, com a presença de cerca de 30 famílias. "A partir de agora, por meio dos grupos pós-oficinas, o participante terá um espaço para debater o que vivenciou nas oficinas e contará com o apoio de um profissional da área de Psicologia. Certamente a nova parceria com a Uninove trará mais uma ferramenta de expansão de consciência àquele que se encontra envolvido em um litígio familiar", disse a magistrada. (TRIBUNAL DE SÃO PAULO, 2020, online)
\end{abstract}

Logo, a estrutura e espaço abertos com as oficinas de parentalidade promovem o aproveitamento de novas técnicas já disseminadas na sociedade e que podem colaborar na resolução de conflitos junto ao Judiciário. O consenso é a melhor saída quando se tem um conflito, e muitas técnicas podem auxiliar o Judiciário em sua missão de implantação da cultura da paz e do consenso, superando a já estabelecida cultura do litígio.

\title{
3.4 Eneagrama
}

Longe de querer esgotar-se o tema, dada a sua complexidade, pretende-se apenas despertar o olhar do leitor à um novo conhecimento, já ofertado em diversas partes do Brasil e do mundo, no formato de curso, e que pode ser realmente útil ao Poder Judiciário, na mesma esteira das constelações sitêmicas, da justiça restaurativa e das oficinas de parentalidade.

O Eneagrama, terminologia grega que pode ser traduzida como "figura de nove pontas", é um mapa geométrico que representa padrões de personalidade humanas e suas complexas relações. Tendo suas raízes em tradições espirituais antigas, encontrase inserido também na psicologia moderna (HUDSON; RISO, 2018) 
https://doi.org/10.20873/uft.2359-0106.2020.v7n2.p426-448

Sendo uma sabedoria antiga, na modernidade tem sido cada vez mais estudada e desenvolvida, em diálogo com correntes filosóficas e psicológicas. No século XX, Gurdjieff, apresentou aos seus alunos um complexo de nove pontos, mas não se referenciou com o nome do eneagrama. (MELENDO, 2004).

Na década de 1950, Oscar Ichazo vinculou o complexo de nove pontas aos nove tributos divinos que representam a natureza humana, proveniente dos princípios cristãos. A partir daí começou a surgiu a ligação entre o eneagrama e os tipos de personalidade (HUDSON; RISO, 2018). A partir de 1960, Ichazo inicia aulas sobre o conhecimento do eneagrama, o que foi posteriormente inserido nas formações de psicologia e espiritualidades (MELENDO, 2004).

Afinal, em 1970, o médico psiquiatra Claudio Naranjo relacionou os tipos do eneagrama às peculiaridades psiquiátricas que conhecia, iniciando a ampliar os sucintos relatos de Ichazo e montando um mecanismo de tipologias, que seria chamado de eneagrama das personalidades. (RISO; HUDSON, 2018; MELO, 2018).

Desde então, o eneagrama tem evoluído e se disseminado nos meios sociais por meio de cursos, promovendo o autoconhecimento, desenvolvimento pessoal e profissional, e alcançando resultados positivos também no âmbito da resolução de conflitos. Neste sentido, afirma-se:

Uma demanda recorrente é a de resolução de conflitos, e para isso, é excelente o exercício fenomenológico de vivenciar a situação, a partir do não julgamento, colocando-se no tapete do Eneagrama, na sua posição e na das demais pessoas envolvidas. É um exercício de tomada de consciência pela experiência, de todas as perspectivas da situação. Nesse exercício, em cada ponto, acompanhamos o cliente na percepção de seus pensamentos, sentimentos, sensações no corpo e comportamentos [...] (ANDREAZZA, 2018, p. 72)

No âmbito jurídico, de forma pacata, o eneagrama tem sido também aplicado com sucesso, como é o caso do sistema penitenciário de Rondônia, onde a população carcerária tem acesso aos cursos, por meio da Associação Cultural e de Desenvolvimento do Apenado e Egresso (Acuda) (RONDÔNIA, 2008).

Além disso, magistrados do Tribunal de Justiça do Tocantins também cursaram toda a formação em eneagrama. $O$ juiz Luatom Bezerra Adelino de Lima relata: 
https://doi.org/10.20873/uft.2359-0106.2020.v7n2.p426-448

buscando diferenciar o dito do não dito, do provável ao improvável acontecido [...] (MELO, 2018, online)

O eneagrama é, ainda, um conhecimento que dialoga com as constelações sistêmicas de Hellinger (MELO, 2018). Acredita-se que a aproximação também do eneagrama com o Poder Judiciário pode trazer inúmeros benefícios.

As oficinas de parentalidade, por exemplo, são estruturas viáveis para aplicação do eneagrama voltado à resolução de conflitos familiares, tornando-se uma técnica auxiliar aos métodos autocompositivos. Por sua vez, os ciclos restaurativos são também ambientes propícios à aplicação do eneagrama, que pode contribuir muito com a ressocialização do apenado.

\section{CONSIDERAÇÕES FINAIS}

A sociedade atual é caracterizada pela elevada conflitualidade e também pela judicialização do cotidiano, que transfere para as mãos do Poder Judiciário a responsabilidade de dirimir todas as questões, inclusive as mais simples.

Conclui-se que, ao vislumbrar a possibilidade da modificação do paradigma de uma cultura litigiosa para uma cultura do consenso, deve-se observar o quanto foi importante e inovadora a decisão do CNJ em relação às resoluções que foram aderidas pelo ordenamento jurídico brasileiro, que apresentou resultados positivos, na aplicação dos métodos autocompositivos e também com relação aos incentivos às técnicas auxiliares que compõem o direito sistêmico.

Técnicas auxiliares, como a constelação familiar e o eneagrama, atuam no meio social, tendo obtido resultados positivos na resolução de conflitos, notadamente os de cunho familiar. Logo, podem ser utilizadas em oficinas de parentalidade promovidas pelos CEJUSCs, como auxiliares ao processo de mediação e obtenção de acordos positivos para as partes em litígio. 


\section{REFERÊNCIAS}

ANDREAZZA, Ana Maria. Conduzindo processos de coaching à luz do eneagrama a serviço da essência. In: CUNHA, Domingos e colaboradores. Eneagrama Sementes. Fortaleza: IESh, 2018.

ASSOCIAÇÃO DOS NOTÁRIOS E REGISTRADORES DO BRASIL. Cartórios ajudam a desburocratizar o sistema judiciário brasileiro. Disponível em:

https://www.anoreg.org.br/site/2019/10/21/irtdpj-br-cartorios-ajudam-a-desburocratizaro-sistema-judiciario-brasileiro/. Acesso em: 09 mar. 2020.

BANDEIRA, Regina. Relatório Justiça em números traz índice de conciliação.

Brasília. Agência CNJ de Notícias, 2016. Disponível em: https://www.cnj.jus.br/relatoriojustica-em-numeros-traz-indice-de-conciliacao-pela-1-vezl. Acesso em: 06 mar. 2020

BRAGA NETO, Adolfo; SALES, Lilia Maia de Morais. Aspectos atuais sobre a mediação e outros métodos extra e judiciais de resolução de conflitos. Rio de Janeiro: GZ, 2012.

BRAGA, Maria do Socorro Pelaes. Justiça Restaurativa: benefícios para sociedade e para a justiça formal. 53F. Trabalho de Conclusão de Curso de Altos Estudos de Política e Estratégia. Rio de Janeiro, ESC, 2014. Disponível em:

http://livrozilla.com/doc/1139475/braga--maria-do-socorro-pelaes.-justi\%C3\%A7arestaurativa--ben. Acesso em: 15 set. 2019.

BRASIL, Conselho Nacional de Justiça. Relatório Justiça em Números 2015.

, Conselho Nacional de Justiça. Relatório Justiça em Números 2016.

, Conselho Nacional de Justiça. Relatório Justiça em Números 2019.

. Lei n. 13.140, de 26 de junho de 2015. Dispõe sobre a mediação entre particulares como meio de solução de controvérsias e sobre a autocomposição de conflitos no âmbito da administração pública; altera a Lei n. 9.469, de 10 de julho de 1997, e o Decreto n. 70.235, de 6 de março de 1972; revoga o $\S^{\circ}$ do art. $6^{\circ}$ da Lei $n$. 9.469, de 10 de julho de 1997. In: Diário Oficial da União, Brasília, DF, 29 jun. 2015. Disponível em: https://www2.camara.leg.br/legin/fed/lei/2015/lei-13140-26-junho-2015781100-publicacaooriginal-147366-pl.html. Acesso em: 03 dez. 2019.

.Lei no 13.105 de 16 de março de 2015. Código de Processo Civil. In: Diário Oficial da União, Brasília, DF, 16 mar. 2015. Disponível em:http://www.planalto.gov.br/ccivil 03/ ato2015-2018/2015/lei/l13105.htm. Acesso em: 20 dez. 2019.

.Lei no 5.869 de 11 de janeiro de 1973. Código de Processo Civil. In: Diário Oficial da União, Brasília, DF, 11 jan. 1973. Disponível em: 
https://doi.org/10.20873/uft.2359-0106.2020.v7n2.p426-448

https://www2.camara.leg.br/legin/fed/lei/1970-1979/lei-5869-11-janeiro-1973-357991publicacaooriginal-1-pl.html. Acesso em: 20 dez. 2019.

.Lei oㅜ 9.099 de 26 de setembro de 1995. Dispõe sobre os Juizados Especiais Cíveis e Criminais e dá outras providências. In: Diário Oficial da União, Brasília, DF, 26 set. 1995. Disponível em: http://www.planalto.gov.br/ccivil 03/leis/19099.htm\#art96. Acesso em 10 dez. 2019.

.Conselho Nacional de Justiça. Justiça Restaurativa. 2017. Disponível em: https://www.cnj.jus.br/programas-e-acoes/justica-restaurativa/. Acesso em: 11 out. 2019.

.Conselho Nacional de Justiça. Perguntas e Respostas. 2017.

Resolução n. 125, de 29 de novembro de 2010. Dispõe sobre a Política Judiciária Nacional de tratamento adequado dos conflitos de interesses no âmbito do Poder Judiciário e dá outras providências. In: Diário de Justiça Eletrônico, Brasília, DF, 30 mar. 2011. Disponível em:https://atos.cnj.jus.br/atos/detalhar/atosnormativos?documento=156. Acesso em 05 jan. 2020.

BRITO, Marcella Mourão de; SILVA, Alexandre Antônio Bruno da. A mediação familiar e o fim do relacionamento conjugal: o problema do acesso à justiça e a experiência das oficinas de parentalidade. Formas Consensuais de Solução de Conflitos, Maranhão, n. 2, 2017.

CABRAL, Trícia Navarro Xavier. A evolução da conciliação e mediação no Brasil. FONAMEC, Rio de Janeiro, n.1, 2017.

CARMO, Maria Scarlet do. Uma Breve Apresentação sobre a Constelação Sistêmica Fenomenológica. Atlas, 2015.

DELGADO, Maurício Godinho. Curso de direito do trabalho. São Paulo: LTr, 2017.

FARIAS, Juliana Guanaes Silva de Carvalho. Panorama da Mediação no Brasil: Avanços e Fatores Críticos Diante do Marco Legal. Direito UNIFACS, n. 188, 2016. Disponivel em:https://revistas.unifacs.br/index.php/redu/article/view/4099/2812. Acesso em: 11 out. 2019.

HAUSNER, Stephan. As constelações familiares e o caminho da cura. São Paulo: Cultrix, 2007. Disponivel em: https://docero.com.br/doc/n0s11sv. Acesso em 09 dez. 2019.

HELLINGER, Bert. Ordens do Amor. Um Guia Para o Trabalho com Constelações Familiares. São Paulo: Cultriz, 2001.

. Simetria oculta do amor. São Paulo: Cultrix, 2015. 
GONÇALVES, Jéssica; LAHOZ, Maria Alice Trentini; RODRIGUES, Horácio Wanderlei. Mediação na resolução cnj n. $.125 / 2010$ e na lei n. $.13 .105 / 2015$ (ncpc): uma análise crítica. Direitos sociais e políticas publicas (UNIFAFIBE), São Paulo, n.1, 2018.

MEDEIROS NETO, Elias Marques de; NUNES, Juliana Raquel. A importância da mediação para o acesso à justiça: uma análise à luz do cpc/2015. Revista Eletrônica de Direito Processual, Rio de Janeiro, n. 2, 2019.

MELENDO, Maite. O eneagrama. São Paulo: Loyola, 2004.

MELO, Claudia Maria de. Eneagrama e Hellinger Sciencia em uma aplicação prática com magistrados no Tocantins. In: CUNHA, Domingos e colaboradores. Eneagrama Sementes. Fortaleza: IESh, 2018.

MERLEAU-PONTY, Maurice. Fenomenologia da percepção. São Paulo: Martins Fontes, 1999.

MOORE, Christopher W. O processo de Mediação: Estratégias Práticas para a Resolução de Conflito. Porto Alegre: Artmed, 1998.

NEUHAUSER, Johannes (org.). Para que o amor dê certo: o trabalho terapêutico de Bert Hellinger com casais. São Paulo: Cultrix, 2006.

NUPEMEC. Justiça Restaurativa. 2011. Disponível em:

http://www5.tjba.jus.br/conciliacao/index.php?option=com_content\&view=article\&id=10\& It emid=24. Acesso em: 09 dez./ 2019.

OLIVEIRA, Ninah Beatriz. Oficinas de Parentalidade estimulam conciliação nas Varas da Família. Disponível em: http://www.tjto.jus.br/index.php?option=com_content\&view=article\&id=4834:oficinas-deparentalidade-estimulam-conciliacao-nas-varas-da-familia\&catid=8\&ltemid=123. Acesso em: 22 fev. 2020.

ORTEGAL, Leonardo Rodrigues de Oliveira. Justiça restaurativa: uma via para a humanização da justiça. Orientador: Potyara Amazoneida Pereira. 62F. Trabalho de Conclusão de Curso de Serviço Sociais. Brasília, Unb, 2006.

HUDSON, Russ; RISO, Don Richard. A Sabedoria do Eneagrama. Cultrix: São Paulo, 2018.

RONDÔNIA. Plano diretor do sistema penitenciário do Estado de Rondônia. 2008. Disponível em:https://www.mpro.mp.br/documents/10180/580287/Plano+Diretor+Sistema+Penitenc i\%C3\%A1rio+RO.pdf/b9d96f4b-c04f-4177-a931-d6450633e57a> Acesso em: 01 mar. 2020. 
SALES, Lília Maia de Morais. A mediação de conflitos - lidando positivamente com as emoções para gerir conflitos. Pensar, Fortaleza, 2016.

. A mediação de conflitos e a pacificação social: Família, Escola e comunidade. Florianópolis: Conceito Editorial, 2007.

SANTOS, Karinne Emanoela Goettems dos. Os Centros Judiciários d,e Solução de Conflitos e Cidadania (CEJUSCS): a autocomposição em perspectiva. Revista da Faculdade de Direito da Ufrgs, Porto Alegre, n.38, 2018.

SCAVONE JUNIOR, Luiz Antonio. Manual de arbitragem: mediação e conciliação. Rio de Janeiro: Rev. e Atual, 2018.

SILVA, Elenice da. Combate ao bullyng: por meio de princípios e práticas da justiça restaurativa. Curitiba: InterSaberes, 2017.

SOUZA, Ana Carolina de Jesus. O cejusc como incentivo á autocomposição na resolução de conflitos: em busca da pacificação social. Ciências humanas e sociais, Aracaju, n. 2, 2019.

TARTUCE, Fernanda. Mediação nos conflitos civis. Rio de Janeiro: Forense, 2019.

Tribunal de Justiça de São Paulo. Disponível em: https://tjsp.jusbrasil.com.br/noticias/688636425/oficina-de-constelacao-familiar-do-cejusc-doforo-regional-de-santo-amaro-completa-um-ano. Acesso em: 25 jan. 2019.

\section{. Oficina de Constelação Familiar do Cejusc do Foro Regional de Santo} Amaro completa um ano. Disponível em:https://tjsp.jusbrasil.com.br/noticias/688636425/oficina-de-constelacao-familiar-do-cejusc-doforo-regional-de-santo-amaro-completa-um-ano. Acesso em: 11 fev. 2020.

TRIBUNAL DE JUSTIÇA DO DISTRITO FEDERAL E DOS TERRITÓRIOS. Disponível em: https://www.tjdft.jus.br/informacoes/cidadania/nupemec/cidadao/oficina-deparentalidade. Acesso em: 23 dez. 2019.

XVI SEMINÁRIO INTERNACIONAL DEMANDAS SOCIAIS E POLÍTICAS PÚBLICAS NA SOCIEDADE CONTEMPORÂNEA, 2019, Santa Cruz do Sul. O DIREITO SISTÊMICO: A APLICAÇÃO DAS TÉCNICAS DE CONSTELAÇÕES FAMILIARES PARA TRATAMENTO DOS LíTIGIOS NAS VARAS DE FAMíLIA. Santa Cruz do Sul: 2019. 17 p. Disponível em:

https://online.unisc.br/acadnet/a+nais/index.php/sidspp/article/view/19650/1192612364. 